\title{
Lingual thrombosis presenting as tongue carcinoma
}

\author{
Elisabeth Arndal, Claus Barfoed, Eva Rye Rasmussen \\ Ear-Nose and Throat Department, Koege Hospital, Denmark \\ Correspondence: Elisabeth Arndal. Address: ENT Department, Koege Hospital, Lykkebaekvej 14600 Koege, Denmark. \\ E-mail: elisabetharndal@hotmail.com \\ Received: February 8, 2014 \\ Accepted: April 22, 2014 \\ Online Published: April 29, 2014 \\ DOI : $10.5430 /$ crcp.v1n2p67 \\ URL: http://dx.doi.org/10.5430/crcp.v1n2p67
}

\section{Abstract}

We report a case of a 57-year old man who was admitted to our department with a necrotic ulcer of the tongue. Carcinoma of the tongue was initially suspected and incisional biopsies were performed along with Magnetic Resonance Imaging of the head and neck and a Computerized Tomography of the head, neck and thorax. The images were normal and the biopsies surprisingly did not show malignancy but venous thrombosis. The patient experienced complete remission without treatment. When re-examining the biopsies the pathologist was unable to rule out vasculitis as a possible cause, because the specimen lacked the appropriate sized vessels for diagnostics. We would like to emphasize that vasculitis should always be considered as a differential diagnosis, when biopsies turn out non-malignant in a patient with a necrotic ulcer of the tongue.

\section{Key words}

Infarction, Thrombosis, Lingual pathology, Tongue cancer, Necrosis, Vasculitis

\section{I ntroduction}

Necrosis of the tongue is a condition that needs immediate medical attention in order to preserve tongue function and thus the patient's ability to eat and speak. An ischemic lesion of the tongue is caused by decreased blood flow and causes pain, swelling, discoloring, necrosis, foetor ex ore and eventually impaired movement of the affected area due to necrosis of the lingual muscle tissue ${ }^{[1,2]}$. Several conditions can cause tongue necrosis and the clinical distinction may thus be difficult. A necrotic ulcer is also one of the most common clinical findings in tongue carcinoma and malignancy should therefore always be suspected. Ninety percent of oral cavity cancers are squamous cell carcinomas (OSCC); the tongue being the most common location. Overall survival rates are low for OSCC (56\%) and a timely diagnosis is vital in order to ensure optimal treatment ${ }^{[3,4]}$. The most important differential diagnosis is vasculitis, which is known to be associated with an increased risk of thrombosis ${ }^{[5]}$. Giant cell arteritis (GCA) represents the most common systemic vasculitis and is known to cause necrosis of the tongue in some patients ${ }^{[6-9]}$. Typical GCA symptoms are headache, scalp tenderness, jaw claudication and in some cases also acute visual loss. GCA has predominance for affecting the external carotid artery and its branches ${ }^{[9]}$. Other causes of tongue necrosis include trauma, infection, previous irradiation of the head and neck ${ }^{[10]}$, vascular embolization and arteriosclerosis ${ }^{[2,11,12]}$ antiphospholipid syndrome ${ }^{[13]}$ and systemic lupus erythematosus ${ }^{[14]}$. A biopsy is essential in the diagnostic work-up, making the pathologist's evaluation of the biopsy a cornerstone in securing a timely and accurate diagnosis, which in turn determines the appropriate line of treatment for the patient. 


\section{Case presentation}

A 57-year old Caucasian male, with a history of alcohol abuse and heavy smoking, was admitted to our department of otorhinolaryngology with a painful, swollen and discolored tongue. He had severe difficulties in swallowing and with articulation. The patient was unable to account for the duration of the symptoms but denied any prior trauma or signs of infection. The clinical examination revealed a foul smelling necrotic lesion, measuring $3 \mathrm{~cm}$ across the inferior aspect of the tongue (see Figure 1). The lesion, and the anterior part of the floor of the mouth, felt firm on palpation, but sensitivity on the tip of the tongue seemed normal. Fresh bleeding occurred when the mucosa was punctured with a thin needle. The remaining clinical examination was normal; in particular the patient was afebrile and had a normal blood pressure, normal vision and displayed no headache or other neurological or rheumatic symptoms. Due to previous alcohol abuse the patient was taking vitamin B and Antabus ${ }^{\circledR}$ (disulfiram) at the time of admission. Given the patient's history of tobacco and alcohol abuse, cancer was highly suspected with a possible secondary infection. The initial blood analyses showed signs of infection (C-reactive protein: $114 \mathrm{mg} / \mathrm{L}$ [normal value $<8.0 \mathrm{mg} / \mathrm{L}$ ], white blood cell count $11.9 \times 10^{9} / \mathrm{L}$ [normal range $\left.\left.3.5-8.8 \times 10^{9} / \mathrm{L}\right]\right)$ and the patient was treated with intra venous metronidazole and cefuroxime.

Figure 1. A swollen and discolored tongue, with a necrotic lesion along the inferior part of the tongue.

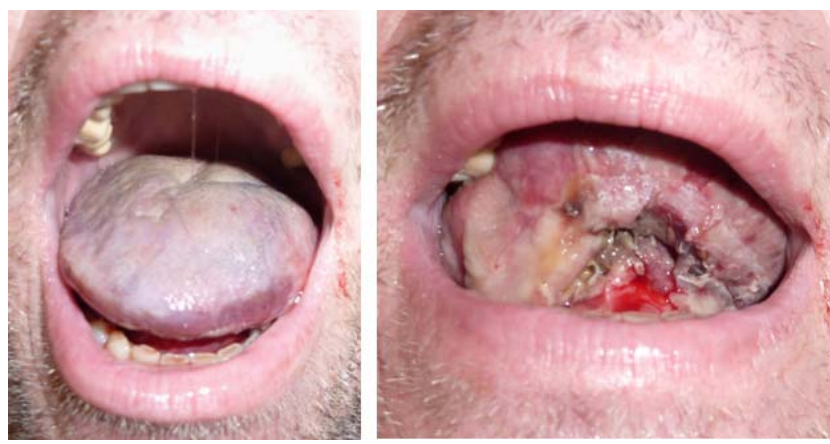

Figure 2. A histological section of the tongue showing tissue necrosis and thrombosis of minor vessels (arrow).

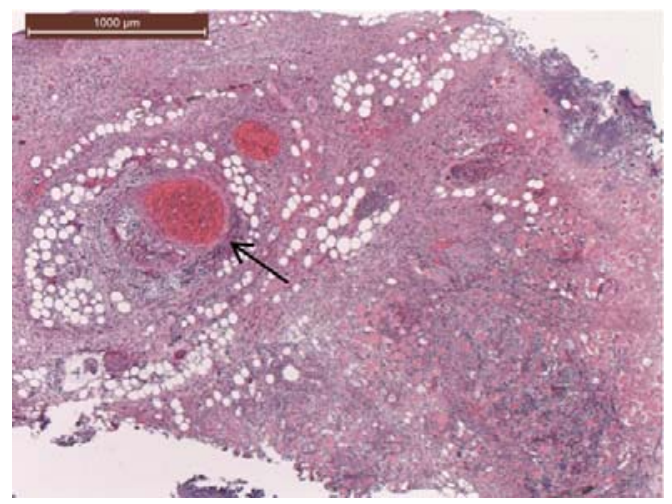

Due to the suspicion of cancer two incisional biopsies were performed and Magnetic Resonance Imaging (MRI) (combined with intravenous contrast) of the head and neck and a Computerized Tomography (CT) scan of the head, neck and thorax were performed. On the second day of admission the swelling had diminished significantly. Blood analyses showed diminishing signs of infection and the medication was changed to oral metronidazole and amoxicillin with clavulanic acid continuing for another six days. On day four the tongue had regained its normal color and only a superficial layer of fibrin was observed on the inferior aspect of the tongue. The patient still experienced some oral pain and difficulty when swallowing. The primary pathology report described two large incision biopsies of the tongue measuring $10 \mathrm{~mm} \times$ $6 \mathrm{~mm} \times 3 \mathrm{~mm}$ and $12 \mathrm{~mm} \times 5 \mathrm{~mm} \times 3 \mathrm{~mm}$ respectively. The tissue comprised of squamous surface epithelia, lamina propria and muscle. The necrosis expanded into all three layers and showed significant infiltration of neutrophile granulocytes. Thrombosis of several minor vessels was noted, but no malignant cells were found. The histopathological conclusion was venous thrombosis (see Figure 2). The MRI and CT showed no other sign of pathological lesions; especially no suspicion of malignancy was raised. The patient was discharged and referred to the rheumatology department for evaluation of possible vasculitis. Unfortunately the patient did not turn up for this evaluation. The 
rheumatologist noted, after reviewing the case that the clinical information and the pathology report were not typical of vasculitis. At the final follow-up appointment in our outpatient clinic, the tongue showed total remission and the patient had no complaints, even though some scar tissue had formed (see Figure 3). In order to rule out vasculitis, the pathologist subsequently reexamined the biopsies. The tissue was stained with Elastin-Van Giesum to identify vessels but unfortunately the vessels represented in the biopsies were too small to confirm, or to rule out temporal arteritis.

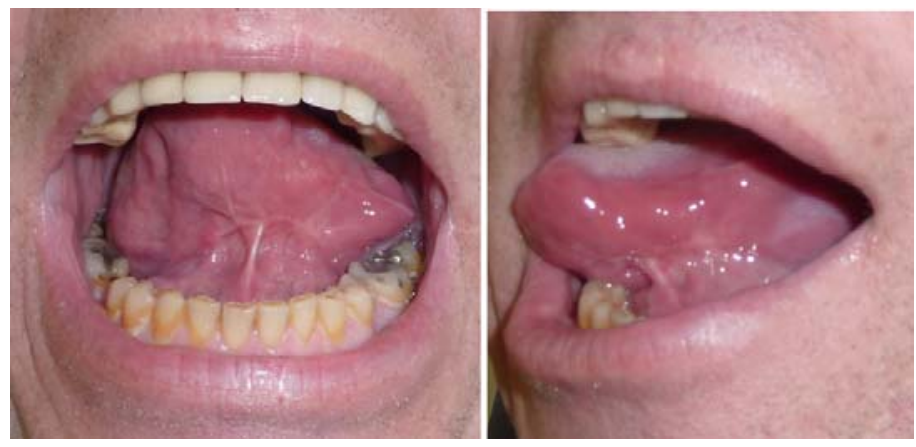

Figure 3. Patient showing total remission with minimal scar-tissue formation

\section{Discussion}

There have been some case reports of lingual thrombosis caused by a wide range of medical conditions, previously described in the literature. Husein-Elahmed et al. reported a case of a 76-year old female with tongue ischemia, raised erythrocyte sedimentation rate and general weakness. The patient quickly improved on corticosteroid treatment and a biopsy of the temporal artery showed temporal arteritis ${ }^{[15]}$. Carter and Brizman reported a case of tongue necrosis secondary to multi-organ dysfunction caused by systemic Wegener's granulomatosis ${ }^{[16]}$. Kagami et al. reported a case of a 62-year old man, with a history of ischemic coronary disease, who developed acute pain, pallor, swelling and ulceration of the tongue. Angiography showed occlusion of the right external carotid, facial and lingual artery. The patient was treated with revascularization of the external carotid artery ${ }^{[11]}$. One should think it unexpected to see infarction of the tongue considering the tongue being such vascularized tissue, and primarily receiving its blood supply from the lingual artery of the external carotid artery. However, these arteries are in fact terminal branches with rather minimal anastomosis across the midline of the tongue ${ }^{[17]}$. Finally Lekovic et al. reported a case of a 28-year-old pregnant woman, with a history of second-trimester fetal demise, presenting several lingual vesicular lesions progressing to lingual infarction. A blood sample showed elevated antiphospholipid antibodies (aPLs) and she was diagnosed with antiphospholipid syndrome (APS) ${ }^{[13]}$.

Thrombosis can also occur secondary to infection ${ }^{[10]}$ but it is difficult to determine which comes first: thrombosis leading to necrosis with secondary infection or infection leading to thrombosis and necrosis. Unfortunately our patient was unable to sufficiently account for the order in which his symptoms had appeared. But we believe the infection to be secondary to the thrombosis.

Tobacco abuse is a known oral cavity cancer risk factor ${ }^{[3,4]}$ but whether smoking can possibly cause lingual thrombosis in not fully explored. Smoking is associated with arteriosclerosis; witch in turn would lead to an increased risk of vascular thrombosis ${ }^{[18]}$. Furthermore, a type of vasculitis called Thromboangiitis (TAO) (also known as Buerger's disease), is heavily associated with smoking and vasculitis ${ }^{[9]}$. Smokers in general also have an overall decreased tongue vascularization ${ }^{[19]}$. These facts could suggest that smoking increases the risk of thrombosis in the tongue.

As outlined above, several conditions can cause tongue necrosis and the clinical distinction may therefore be difficult. A necrotic ulcer is one of the most common clinical findings in carcinoma of the tongue and malignancy should be the primary tentative diagnosis in a patient with a history of tobacco and alcohol abuse ${ }^{[20]}$. However vasculitis is an important 
differential diagnosis and biopsies should, when possible, be stained in order to secure vessel wall evaluation. In our case the lack of appropriately sized vessels in the biopsy unabled the pathologist to rule out temporal arteritis as a possible cause when reexamining the biopsies. Unlike patients suffering from vasculitis our patient did not present the classical symptoms of vasculitis and experienced complete remission without corticosteroid treatment ${ }^{[1,2,6-8]}$. The pathological diagnosis is paramount in choosing the correct treatment of a patient with an ulcerous necrosis of the tongue. In the case of a surprisingly benign biopsy, recommendations from the pathologist suggesting common differential diagnoses would be helpful to the clinician. We wish to emphasize the importance of considering vasculitis as a differential diagnosis, when biopsies turn out non-malignant in a patient with tongue necrosis.

\section{Acknowledgements}

The authors would like to thank Dr. Bo Hainau from the pathology department, Roskilde Hospital Denmark for evaluating the biopsies and providing the photo of the histological section. The authors would also like to thank Dr. Kristianna Mey for linguistic editing.

\section{References}

[1] Strome M, Kelly JH. Infarcted tongue. J R Soc Med. 1984 March; 77(3): 244-245. PMid: 6699867.

[2] Sainuddin S, Saeed NR. Acute bilateral tongue necrosis: a case report. Br J Oral Maxillofac Surg. 2008 Dec; 46(8): 671-2. http://dx.doi.org/10.1016/j.bjoms.2008.03.027.Epub 2008 May 21.

[3] Bagan J, Sarrin G, Jimenez Y. Oral cancer: clinical features. Oral Oncol. 2010 Jun; 46(6): 414-7. PMid: 20400366. http://dx.doi.org/10.1016/j.oraloncology.2010.03.009

[4] Akram S, Aamir Mirza M, Qureshi M. Emerging patterns in clinic-pathological spectrum of oral cancers. Pak J Med Sci. 2013 May; 29(3): 783-7. PMid: 24353628.

[5] Gaffo AL. Thrombosis in vasculitis. Best Pract Res Clin Rheumatol. 2013; 27: 57-67. PMid: 23507057. http://dx.doi.org/10.1016/j.berh.2012.12.005

[6] Barfoed CP, Bretlau P. Tongue necrosis in temporal arteritis. Acta Otolaryngol. 1984 Sep-Oct; 98(3-4): 380-4. PMid: 6437132. http://dx.doi.org/10.3109/00016488409107577

[7] Ginzburg E, Evans WE, Smith W. Lingual infarction: a review of the literature. Ann Vasc Surg. 1992 Sep; 6(5): $450-2$. PMid: 1467185. http://dx.doi.org/10.1007/BF02007001

[8] Grant SW, Underhill HC, Atkin P. Giant cell arteritis affecting the tongue: a case report and review of the literature. Dent Update. 2013 Oct; 40(8): 669-70, 673-4, 677.

[9] Brodmann M, Dorr A, Hafner F, Gary T, Pilger E. Tongue necrosis as first symptom of giant cell arteritis (GCA). Clin Rheumatol. 2009 June; 28(Suppl 1): 47-9. PMid: 19277817. http://dx.doi.org/10.1007/s10067-009-1141-z

[10] Gibbs IC, Le QT, Shah RD, Terris DJ, Fee WE, Goffinet DR. Long-term outcomes after external beam irradiation and brachytherapy boost for base-of-tongue cancers. Int J Radiat Oncol Biol Phys. 2003 Oct 1; 57(2): 489-94. http://dx.doi.org/10.1016/S0360-3016(03)00597-2

[11] Kagami H, Inaba M, Icimura S, Hara K, Inamasu J. Endovascular Revascularization of External Carotis Artery Occlusion Causing TongueInfarction. Meurol Med Chir. 2012; 52: 910-13. http://dx.doi.org/10.2176/nmc.52.910

[12] Clement F, Nordhuus J. Ugeskr Laeger. 1993 Aug 9; 155(32): 2475-7. PMid: 8356771.

[13] Lekovic JP, Friedman CM, DeSancho MT. Lingual thrombosis in a woman with antiphospholipid syndrome. Am J Obstet Gynecol. 2013 Apr; 208(4): e3-4. http://dx.doi.org/10.1016/j.ajog.2013. Epub 2013 Jan 8.

[14] Korn S, Huppert A, Spitzer S, DeHoratius RJ. Systemic lupus erythematosus presenting with lingual infarction. J Rheumatol. 1988 Aug; 15(8): 1281-3. PMid: 3184076.

[15] Husein-Elahmed H, Callejas-Rubio JL, Rios-Fernandez R, Ortego-Centeno N. Tongue infarction as first sign of temporal arteritis. Rheumatol Int. 2012; 32: 799-800. PMid: 20058010. http://dx.doi.org/10.1007/s00296-009-1355-z

[16] Carter LM, Brizman E. Lingual infarction in Wegerner’s Granulomatosis: A case report and review of the literature. Head Face Med. 2008 Aug; 4(19). http://dx.doi.org/10.1186/1746-160X-4-19

[17] Du Toit DF. The tongue: structure and function relevant to disease and oral health. SADJ. 2003 Oct; 58(9): 375-6, 380-3. PMid: 14964052.

[18] Rigotti NA, Clair C. Managing tobacco use: the neglected cardiovascular disease risk factor. Eur Heart J. 2013 Nov; 34(42): 3259-67. PMid: 24014389. http://dx.doi.org/10.1093/eurheartj/eht352

[19] Pavlidis P, Gouveris C, Kekes G, Maurer J. Changes in electrogustometry thresholds, tongue tip vascularization, density and form of the fungiform papillae in smokers. Eur Arch Otorhinolaryngol. 2014 Mar; 17. http://dx.doi.org/10.1007/s00405-014-3003-9

[20] Rosenquist K, Wennerberg J, Schildt EB, Bladström A, Göran Hansson B, Andersson G. Oral status, oral infections and some lifestyle factors as risk factors for oral and oropharyngeal squamous cell carcinoma. A population-based case-control study in southern Sweden. Acta Otolaryngol. 2005 Dec; 125(12): 1327-36. PMid: 16303683. http://dx.doi.org/10.1080/00016480510012273 